\title{
ANÁLISE DA LEI DE DEPÓSITO LEGAL BRASILEIRA SOB A ÓTICADE LARIVIĖRE (2000)
}

\author{
MARCIA CARVALHO RODRIGUES*
}

\section{RESUMO}

O presente trabalho apresenta uma revisão teórica sobre o tema do depósito legal de publicações, incluindo uma análise da lei brasileira sobre depósito legal - Lei n. 10.994/2004, à luz das recomendações propostas por Larivière, em sua publicação intitulada Guidelines for legal deposit legislation, publicada em 2000. O estudo aponta mudanças, ao longo da história, das finalidades do depósito legal. O paradigma atual faz com que o objetivo principal do depósito legal convirja para a preservação do patrimônio cultural e para a construção de uma memória documental nacional. A análise da lei brasileira demonstra a necessidade de adequação de alguns aspectos apontados por Larivière (2000). De forma ampla, a lei mostra-se adequada aos propósitos do depósito legal e, consequentemente, aos objetivos do Controle Bibliográfico Universal.

PALAVRAS-CHAVE: Depósito legal. Lei n. 10.994/2004. Controle Bibliográfico Universal.

\begin{abstract}
This paper presents a theoretical review on the subject of legal deposit of publications, including an analysis of brazilian legal depos it law - Law no. 10.994/2004 in the light of the recommendations proposed by Larivière, in its publication entitled Guidelines for legal deposit legislation, published in 2000. The study points changes, throughout history, the purposes of legal deposit. The current paradigm is that the main objective of legal deposit converges to the preservation of cultural heritage and the building of a national documentary memory. The analysis of brazilian law demonstrates the need to adapt some aspects pointed out by Larivière (2000). Broadly speaking, the law appears to be appropriate for the purposes of legal deposit and hence the objectives of the Universal Bibliographic Control.
\end{abstract}

KEYWORDS: Legal deposit. Brazilian Law no. 10.994/2004. Universal Bibliographic Control.

\footnotetext{
* Universidade Federal do Rio Grande - FURG. Doutora em Memória Social e Patrimônio Cultural. E-mail: marciarodriguesfurg@gmail.com.
} 


\section{INTRODUÇÃO}

A origem do depósito legal evoca ideias que envolvem, confusamente, bibliotecas, censura e propriedade intelectual. Através deste estudo, que integra a pesquisa que a autora vem realizando para sua tese de doutoramento, busca-se conhecer a história do depósito legal: como esta prática se desenvolveu no Brasil, seus antecedentes e propósitos.

Este trabalho inclui, além da revisão teórica sobre o tema, uma análise da legislação brasileira sobre depósito legal. A pesquisa, de cunho exploratório-descritivo, apresenta natureza qualitativa e fez uso das técnicas de revisão bibliográfica e documental.

Para a realização da análise da lei brasileira que regulamenta o depósito legal - Lei n. 10.994, de 14 de dezembro de 2004 - utilizou-se, como elemento balizador, o documento Guidelines for legal deposit legislation (2000). Convém elucidar que este documento é o resultado de um estudo iniciado por Jean Lunn, bibliotecária canadense, publicado em 1981. Lunn elaborou a pesquisa a partir de um acordo firmado entre a Organização das Nações Unidas para Educação, Ciência e Cultura (UNESCO) e a Federação Internacional de Associações de Bibliotecários e Bibliotecas (IFLA) durante o Congresso Internacional sobre Bibliografias Nacionais (International Congress on National Bibliographies), ocorrido em 1977, em Paris. Tal evento propôs uma série de recomendações visando à consolidação do Controle Bibliográfico Universal (CBU), dentre as quais havia recomendações específicas sobre 0 depósito legal de publicações. $O$ evento mencionado vem ocorrendo regularmente desde então, e origina, em todas as suas edições, novas recomendações, as quais abarcam, em seu escopo, o sistema de depósito legal.

O objetivo principal do estudo de Lunn consistia, portanto, em "[...] elaborar um modelo de legislação para o depósito legal, que serviria como base para os Estados membros na realização do controle bibliográfico nacional." (LUNN, 1981, p. i, trad. nossa).

O trabalho de Lunn foi, posteriormente, revisado e atualizado, a fim de ampliar a aplicação das orientações a um número maior de países, já que a autora havia se pautado, especialmente, na legislação da Bélgica, Canadá, França, GrãBretanha, Nova Zelândia, Espanha, Suécia e Estados Unidos, com menções ocasionais às leis da Áustria, Dinamarca, Grécia, Israel, Itália, Noruega, Romênia e URRS - ficaram fora da pesquisa as leis 
de países sul-americanos, africanos e asiáticos. Além deste fator, havia também a necessidade de incorporar novas formas de publicação, como as eletrônicas, às recomendações. Dessa forma, em 2000, foi publicada sua edição revista, aumentada e atualizada pelo então diretor da Biblioteca do Direito da Universidade de Ottawa (Canadá), Jules Larivière.

\section{O DEPÓSITO LEGAL: ORIGEM E FINALIDADES}

O sistema de depósito legal tem sua origem na França quando, em 1537, o rei Francisco I, através da Ordonnance de Montpellier, decretou expressamente proibida a venda de livros, a todas as impressoras e livreiros do reino, dos quais não tivesse sido entregue ao menos um (01) exemplar à biblioteca real do Castelo de Blois.

A Ordonnance visava tanto à identificação de obras dignas de memória quanto ao controle da disseminação de ideologias divergentes, haja vista que o rei Francisco I temia a produção de impressos de conteúdo protestante e, dessa forma, buscava controlar o sistema de impressões do reino (DOUGNAC; GUILBAUD, 1960).

O sistema, porém, se mostrou ineficiente na prática, já não era possível seu controle eficaz. Muitos editores, a fim de evitar a censura de suas obras, passaram a enviar seus originais para impressão em países estrangeiros, burlando, assim, a Ordonnance. Devido a esta falha no sistema, foi lançado, em 1617, um novo ato legislativo que vinculava o depósito legal ao sistema de privilégios ${ }^{1}$, o que, por sua vez, pode ser considerado a remota origem da função de proteção da propriedade literária atribuída subsequentemente ao depósito legal francês (DOUGNAC; GUILBAUD, 1960).

A Ordonnance de Montpellier vigorou, sem interrupção, até o início da Revolução Francesa, sempre enfrentando dificuldades na sua aplicação, uma vez que a prática da contrafação (publicação de edições piratas) se tornou cada vez mais comum. Quando a Revolução foi deflagrada, a Ordonnance foi abolida, assim como o privilégio e a censura, em nome da liberdade de expressão.

\footnotetext{
1 "Permissão concedida com exclusividade pelo poder civil, a favor de um editor por tempo determinado e por obra, o que impedia que outro pudesse publicar essa mesma obra durante o tempo de proteção estabelecido." (MARTínEZ DE SOUZA, 1992 apud PINHEIRO, 1995, p. 200).
} 
Em 1793, a Ordonnance foi restaurada na França, exercendo uma nova função: a de proteger os direitos do autor. No novo sistema, a responsabilidade pelo depósito passou a ser do autor, não mais do editor. Obras anônimas, por definição, não precisariam ser enviadas.

Paralelamente ao surgimento da Ordonnance de Montpellier, em 1594, na Bélgica, foi instituído o sistema belga de depósito legal. Este foi abolido em 1886, com a assinatura do Convênio de Berna ${ }^{2}$, uma vez que o Convênio deliberava que o direito do autor não estaria subordinado a nenhuma formalidade. O depósito legal, porém, foi reintroduzido no país em 1966. Outros países que assinaram o Convênio, não tão radicais quanto a Bélgica, optaram por fazer adaptações em suas leis de depósito legal, a fim de não ferirem os princípios básicos do mesmo.

A partir de então, percebe-se que ideia de depósito legal se expandiu pela Europa durante o século XVII, tendo sido adotado mediante legislação específica pelo Reino Unido (1610), Alemanha (1624), Suécia (1661), Dinamarca (1697) e Finlândia (1702). (LARIVIÈRE, 2000; URIBE e STEENKIST, 2005; CAMPELLO, 2006)

A partir do século XVIII, sua relação com o direito de propriedade intelectual se tornou mais íntima, como se observa na própria França, em 1793, com a reintrodução da lei de depósito legal reformulada, a qual, conforme mencionado anteriormente, incorporou, também, a função de proteção à propriedade literária. Em função da implementação do Convênio de Berna, em 1886, todos os países signatários passaram por algum tipo de adaptação de suas normas (com exceção da Bélgica, que simplesmente aboliu o depósito legal no país e o reintroduziu 80 anos mais tarde).

${ }^{2}$ O Convênio de Berna para a Proteção de Obras Literárias e Artísticas, mais conhecido como Convênio de Berna ou Convenção de Berna, foi o primeiro tratado internacional sobre a proteção das obras literárias e artísticas e os direitos dos autores. Firmado em Berna, na Suíça, em 9 de setembro de 1886, passou por oito revisões, tendo sido a última realizada no ano de 1979. Seus três princípios básicos são os seguintes: "a) As obras originárias de um dos Estados Contratantes [...] deverão ser objeto, em todos e em cada um dos demais Estados Contratantes, da mesma proteção que concedem às obras de seus próprios [autores] nacionais (princípio do 'trato nacional'). b) A proteção não deverá estar subordinada ao cumprimento de formalidade alguma (princípio de 'proteção automática'). c) A proteção é independente da existência de proteção no país de origem da obra (princípio de 'independência' da proteção). Contudo, se em um Estado Contratante se prevê um prazo maior de proteção que o mínimo prescrito pelo Convênio, e cessa a proteção da obra no país de origem, a proteção poderá ser negada enquanto es tiv er suspensa no país de origem." (ORGANIZAÇÃO MUNDIAL DA PROPRIEDADE INTELECTUAL, 2015, trad. nossa) 
Em 1908, o Convênio de Berna passou por uma importante revisão que resultou na desvinculação do depósito legal dos direitos de propriedade intelectual, o que, consequentemente, impactou os partícipes do acordo, ocasionando uma reconfiguração de suas leis. Jasion (1991 apud LARIVIĖRE, 2000) destaca em estudo realizado em 1990, a presença de algum tipo de sistema oficial de depósito legal em 139 países, sendo o Brasil $^{3}$ um destes.

Ao investigar diferentes leis sobre depósito legal, observa-se que apresentam como característica comum sua intenção de preservar e tornar acessível à coletividade a herança bibliográfica nacional. Uribe e Steenkist (2005, p. 7, trad. nossa) atentam ainda para o fato de que

O depósito legal também contribui para gerar informação sobre o estado bibliográfico de um país e se converte em uma fonte importante para comparar os níveis de publicação ano a ano, ou mês a mês, segundo o grau de sistematização que tenham as entidades responsáveis.

Corrobora-se com Uribe e Steenkist na medida em que a prática do depósito legal, na atualidade, incorpora-se a um conjunto de medidas que visam ao $\mathrm{CBU}$, cujo principal objetivo está centrado em reunir e tornar disponíveis os registros da produção bibliográfica de todos os países do mundo, criando uma rede internacional de informação.

A legislação sobre depósito legal tem um claro caráter de interesse público, ao garantir a aquisição, o registro, a preservação e a disponibilidade do patrimônio de obras publicadas de um país. Uma coleção nacional desse tipo é, sem dúvida, um dos principais componentes da política cultural de cada país e também deve se considerar como o fundamento da política nacional de liberdade de expressão e acesso à informação. A função do sistema de depósito legal é garantir a criação de uma coleção nacional de material publicado em diferentes formatos. Também deve favorecer a compilação e a publicação de uma bibliografia nacional para garantir o controle bibliográfico de uma coleção de depósito completa. Por último, uma legislação eficaz sobre depósito legal garante aos cidadãos e investigadores do país e do estrang eiro o acesso às coleções de investigação de material publicado no país (LARIVIĖRE, 2000, p. 4, trad. nossa).

${ }^{3}$ O Convênio de Berna foi assinado pelo Brasil em 09 de fevereiro de 1922. 
Ainda sobre a legislação referente ao depósito legal em diferentes países, Larivière (2000) aponta semelhanças nos seus propósitos, porém ressalta existir variações, tanto em relação à determinação do número de exemplares a serem depositados, quanto ao tipo de material a ser depositado (impressos, publicações periódicas, recursos audiovisuais, eletrônicos etc.); e mesmo à existência de legislação específica para o depósito legal, uma vez que, em alguns países, esta se encontra vinculada a outras normas, como a lei de direitos autorais, como é o caso da Argentina, por exemplo:

Em muitos países a disposição através da qual se estabelece o depósito legal figura em uma lei específica (França, Grécia, Indonésia, Noruega, Peru, África do Sul, Suécia), em outros, form a parte de outra lei, por exemplo, a lei sobre direito de autor (Austrália, Estados Unidos, Grã Bretanha), a lei sobre a biblioteca nacional (Canadá, Japão, Nigéria, Venezuela) ou uma "lei sobre bibliotecas" geral (Tasmânia). Em alguns países se publica s ob a forma de decreto ou ordem (Chile, Cuba, Nigéria). (LARIVIÈRE, 2000 , p. 3, trad. nossa).

Ao longo da história do depósito legal, diversas mudanças ocorreram visando à adequação das leis, muitas destas em consequência do surgimento de novos formatos de registro da informação. Da mesma forma, as finalidades do depósito legal, apontadas anteriormente, têm mudado ao longo do tempo: se, na sua origem, este visava à criação de uma coleção de memória somente, com o passar do tempo, foi agregando novas funções, como as já citadas censura e garantia de direitos do autor. A partir dessas considerações, destacam-se quatro finalidades do depósito legal:

1) finalidade cultural, ao buscar a preservação do patrimônio bibliográfico com a criação de uma coleção de memória nacional através dos exemplares compulsoriamente encaminhados à instituição depositária. A finalidade cultural, como se pode observar, está presente desde as suas origens, tendo as outras três finalidades surgido com o passar do tempo, as mudanças sociais e o contexto político vigente.

2) Finalidade social, ao buscar alternativas para proporcionar acesso à coleção de memória bibliográfica nacional. Esta finalidade, delineada mais recentemente, vai ao encontro dos objetivos da elaboração de uma bibliografia nacional. A Conferência Internacional sobre Serviços Bibliográficos Nacionais reitera "[...] o 
valor do depósito legal como meio de assegurar a conservação do patrimônio cultural e intelectual e a diversidade linguística da nação e para que seja acessível aos usuários atuais e futuros." (CONFERÊNCIA INTERNACIONAL SOBRE SERVIÇOS BIBLIOGRÁFICOS NACIONAIS, 2002 apud FEDERAÇÃO INTERNACIONAL DAS ASSOCIAÇÕES DE BIBLIOTECÁRIOS E BIBLIOTECAS, 2009, p. 88).

A finalidade social do depósito legal, por sua vez, vai ao encontro do papel de uma biblioteca nacional, que é, entre outros, o de promoção cultural, criando mecanismos de difusão de suas coleções à sociedade como um todo.

3) Finalidade política, ao servir de instrumento de controle das publicações de um país, possibilitando a elaboração da bibliografia nacional. Sobre a finalidade política, é importante ressaltar que

Uma função importante do depósito legal relacionado com as bibliografias nacionais é ajudar na produção de estatísticas da produção cultural do país e desempenho das indústrias culturais; estatísticas que ajudarão a formular políticas nacionais e setoriais mais adequadas em matéria cultural. (PABÓN CADAVID, 2013, trad. nossa)

4) Finalidade legal, ao assegurar os direitos de propriedade intelectual e os direitos do autor, tornando obrigatório, por força de lei, o envio de 1 ou mais exemplares à instituição competente para fins de registro e tombamento. Sobre essa finalidade, observa-se, apenas, que nem sempre está presente na legislação de alguns países, haja vista a recomendação do Convênio de Berna para que os direitos de propriedade intelectual não estejam subordinados a nenhuma formalidade, excluindo, dessa forma, a vinculação entre o depósito legal e os direitos do autor. Assim, os países que assinaram o Convênio, muito provavelmente já terão revisto suas leis de depósito legal, excluindo qualquer tipo de relação entre este e os direitos de autor.

\subsection{O depósito legal no Brasil}

O depósito legal, no Brasil, é uma exigência, definida por lei, de proceder à entrega à Biblioteca Nacional $(B N)$ de 1 ou mais exemplares de toda publicação editada no país em papel ou em qualquer suporte físico, destinada à venda ou à distribuição gratuita. 
Tal exigência se originou ainda no período Imperial. Concebido, inicialmente, como um sistema de "propinas", consistia na obrigação imposta às oficinas tipográficas portuguesas instaladas em solo brasileiro do envio de exemplares de suas publicações para a Real Biblioteca, instalada no Rio de Janeiro em 1810, à semelhança das deliberações impostas pela Ordonnance de Montpelier, na França quinhentista.

Em 1822, com a Independência do Brasil, houve a transferência da fiscalização do sistema de propinas à Imprensa Régia, a qual deveria enviar à Biblioteca Imperial e Pública da Corte (nova denominação da Real Biblioteca) as publicações impressas, assim permanecendo até 1907, quando o Decreto n. 1.825 regulou a remessa de livros à Biblioteca Nacional.

Manda Sua Magestade o Imperador, pela secretaria de Estado dos Negocios do Imperio, que a Junta Directoria da Typografia Nacional, faça remetter para a Biblioteca Imperial e Publica desta Corte hum exemplar de todas as obras, folhas periodicas, e volantes, que se imprimirem na mesma Typografia, e de quaesquer reimpressões, que alli se fizerem, e na occazião em que se publicarem, ou se expozerem á venda, por ser mui prejudicial ao Serviço Publico toda a demora, que houver, na mencionada remessa (BRASIL, 1822 apud PINTO, 2011, p. 108).

O Aviso de 12 de novembro de 1822, acima transcrito, é o primeiro documento oficial a ser redigido regulando o depósito legal no Brasil. Pinto (2011) destaca não ter sido dada atenção ao depósito legal pela maior parte dos diretores que passaram pela Biblioteca Nacional em seus registros, o que impossibilita a obtenção de maiores informações sobre o tema, especialmente no período que vai de 1822 a 1847, quando surge o Decreto n. 433, de 3 de julho de 1847.

Esta legislação trazia em seu texto novidades, já que além de determinar o envio das obras impressas na Corte para a Biblioteca Imperial, determinava que os impressos que fossem publicados nas províncias deviam ser remetidos para as bibliotecas das capitais das respectivas províncias. (PINTO, 2011, p. 51).

Seis anos após, o Decreto n. 1.283, de 26 de novembro de 1853, atualiza, aprova e manda observar as instruções para a execução do Decreto n. 433/1847. Em relação ao anterior, apresentava as seguintes inovações: 
- aplicação de sanções em caso de descumprimento e comunicação à autoridade encarregada da punição (promotor público);

- inclusão das obras musicais, dos mapas, das estampas e das gravuras como publicações passíveis de depósito;

- extensão do depósito para as reimpressões e novas edições;

- inclusão das obras que trazem indicação da cidade do Rio de Janeiro, mes mo que tenham sido impressas em outros locais;

- extensão de todas as instruções para as bibliotecas das províncias, que recebiam, nesse caso, as publicações locais. (PINTO, 2011, p. 52)

O Decreto n. 1.283/1853 vigorou até 20 de dezembro de 1907, quando foi substituído pelo Decreto n. 1.825. Este, por sua vez, determinava o envio de 1 exemplar de cada obra que os administradores de oficinas de tipografia, litografia, fotografia ou gravura produzissem (BRASIL, 1907). De acordo com o Decreto,

$\S 1^{0}$ Estão comprehendidos na disposição legal não só livros, revistas e jornaes, mas tambem obras musicaes, mappas, plantas, planos e estampas.

$\S 2^{\circ}$ Applicar-se-ha a mesma disposição aos sellos, medalhas e outras especies numismaticas, quando cunhadas por conta do Governo.

$\S 3^{\text {a }}$ Consideram-se como obras differentes as reimpressões, novas edições, ensaios e variantes de qualquer ordem. (BRASIL, 1907, Art. 1)

A partir do Decreto n. 1.825/1907, a abrangência da aplicação da lei alcançou o nível da federação, estendendo-se a todos os estados. Acrescentaram-se, também, outros tipos de materiais passíveis de depósito, conforme se observa no parágrafo 2 do Art. $1^{\circ}$ - selos, medalhas e outras espécies numismáticas que tenham sido cunhadas para o governo. Além destas novidades, houve também a implementação da multa em caso de descumprimento e o estabelecimento de um prazo máximo para envio das obras. Em $1^{\circ}$ de junho de 1908, foram publicadas, pelo ministro da Justiça e Negócios Interiores, as instruções para a execução do Decreto, as quais acrescentam os anúncios, cartões postais e imagens que se destinem à venda ou à ampla distribuição ao público, além das edições que apresentassem diferenças de formato, papel ou cor de tinta. Novas instruções foram publicadas em 1922 e 1930.

Após a regulamentação do depósito legal, através do Decreto n. 1.825/1907, inúmeras reformulações e atualizações das suas 
instruções foram propostas, sem, no entanto, receber a devida atenção. Somente em 1988, através do Projeto de Lei do Senado n. 110 (equivalente ao Projeto de lei da Câmara n. 3.803, de 1989), de autoria do Senador Jarbas Passarinho, surge a proposta que viria a consolidar, quinze anos mais tarde, a lei que regula o depósito legal no Brasil da atualidade: a Lei n. 10. 994 de 14 de dezembro de 2004.

A Lei 10.994/2004 apresenta, em relação ao Decreto 1.825/1907, uma série de inovações, tais como:

1) Sanções:

a) a atualização da multa em caso de não cumprimento do depósito: o decreto previa multas com valores fixos de 50 e $100 \mathrm{mil}$ réis; a lei prevê multa correspondente a até cem vezes o valor da obra no mercado;

b) a atualização da penalidade de apreensão de exemplares em caso de não cumprimento do depósito, adequando a quantidade de exemplares a ser apreendida às necessidades da instituição, para fins de complementação de coleção.

2) Definições: apresenta quatro definições pertinentes: Distribuição ou divulgação, Editor, Impressor e Depósito legal:

Depósito legal: exigência estabelecida em lei para depositar, em instituições específicas, um ou mais exemplares, de todas as publicações, produzidas por qualquer meio ou processo, para distribuição gratuita ou venda. (BRASIL, 2004, Art. 2, § 1)

3) Objeto: na definição de depósito legal, a Lei 10.994 já demonstra quais são os objetos passíveis de depósito: publicações em qualquer suporte físico, o que, por sua vez, acaba com o problema ocasionado pelo surgimento de novos suportes e a dúvida sobre a obrigatoriedade de depósito legal destes. No decreto, os tipos de obra passíveis de depósito eram enumerados um a um: livros, revistas e jornais, obras musicais, mapas, plantas, planos e estampas, selos, medalhas e outras espécies numismáticas cunhadas por conta do Governo.

A este respeito, é importante salientar que, em 14 de janeiro de 2010, foi promulgada a Lei n. 12.192, que, juntamente com a Lei $n$. 10.994/2004, regula o depósito legal de publicações no país, sendo a primeira responsável pelo registro, guarda e divulgação da produção musical brasileira e a preservação da memória fonográfica nacional. Para tanto, considera obras musicais "[...] partituras, fonogramas e videogramas musicais, produzidos por qualquer meio ou processo, para distribuição gratuita ou venda." (BRASIL, 2010, Art. $2^{\circ}$ ). 
4) Transporte: o Decreto 1.825 previa a isenção de franquia e gratuidade de registro aos depositantes que enviassem suas obras pela Empresa Brasileira de Correios e Telégrafos. Esta isenção passa a não ter mais validade com a Lei 10.994, uma vez que fica estabelecido que "As despesas de porte decorrentes do depósito legal são de responsabilidade exclusiva dos respectivos depositantes." (BRASIL, 2004, Art. 6).

5) Prazo: o Decreto previa o envio das obras em um prazo de até cinco dias após a sua publicação; a Lei prevê o prazo de até trinta dias após a sua publicação.

6) Número de exemplares a serem enviados: o Decreto previa o envio de apenas 1 exemplar; a Lei menciona 1 ou mais exemplares.

7) Objetivos: o Decreto não esclarece a finalidade e objetivos do depósito legal, apenas determina que o mesmo seja cumprido. A Lei 10.994, por sua vez, clarifica:

Esta Lei regulamenta o depósito legal de publicações, na Biblioteca Nacional, objetivando asseguraro registro e a guarda da pro dução intelectual nacional, além de possibilitaro controle, a elaboração e a divulgação da bibliografia brasileira corrente, bem como a defesa e a presenação da língua e cultura nacionais. (BRASIL, 2004, Art. 1)

No que tange à legislação brasileira sobre o depósito legal, observa-se, portanto, a seguinte cronologia:

\begin{tabular}{|c|c|l|}
\hline Ano & Documento & \multicolumn{1}{c|}{ Conteúdo } \\
\hline 1822 & $\begin{array}{c}\text { Aviso de 12 de } \\
\text { novembro de 1822 }\end{array}$ & $\begin{array}{l}\text { Manda remeter para a Biblioteca Imperial e } \\
\text { Pública da Corte um exemplar de todas as } \\
\text { obras, folhas periódicas, e volantes, que se } \\
\text { imprimirem na mesma Tipografia, e de } \\
\text { quaisquer reimpressões, que ali se fizerem. }\end{array}$ \\
\hline 1847 & $\begin{array}{c}\text { Decreto n. 433, de 3 de } \\
\text { julho de 1847 }\end{array}$ & $\begin{array}{l}\text { Obriga os impressores a remeter, na Corte à } \\
\text { Biblioteca Pública Nacional, e nas províncias à } \\
\text { biblioteca da capital, umexemplar de todos os } \\
\text { impressos que saírem das respectivas } \\
\text { tipografias. }\end{array}$ \\
\hline 1853 & $\begin{array}{c}\text { Decreto n. 1.283, de 26 } \\
\text { de novembro de 1853 }\end{array}$ & $\begin{array}{l}\text { Atualiza, aprova e manda observar as } \\
\text { instruções para a execução do Decreto } \\
\text { n. 433/1847. }\end{array}$ \\
\hline 1865 & $\begin{array}{l}\text { Avison. 141, de 24 de } \\
\text { março de 1865 }\end{array}$ & $\begin{array}{l}\text { Sobre a execução da providência que se } \\
\text { tomou para se fazer efetiva a remessa dos } \\
\text { impressos que saem das tipografias da cidade } \\
\text { do Rio de Janeiro à Biblioteca Nacional. }\end{array}$ \\
\hline 1907 & $\begin{array}{c}\text { Decreto n. 1.825, de 20 } \\
\text { de dezembro de 1907 }\end{array}$ & $\begin{array}{l}\text { Dispõe sobre a remessa de obras à } \\
\text { Biblioteca Nacional. }\end{array}$ \\
\hline
\end{tabular}




\begin{tabular}{|c|c|c|}
\hline 1908 & $\begin{array}{l}\text { Tnstruções do Ministério } \\
\text { da Justiça e Negócios } \\
\text { Interiores, de } 01 \text { de } \\
\text { junho de } 1908\end{array}$ & $\begin{array}{l}\text { Atualiza e manda observar as instruções } \\
\text { para a execução do Decreto n. } 1.825 / 1907 \text {. }\end{array}$ \\
\hline 1922 & $\begin{array}{l}\text { Instruções do Ministério } \\
\text { da Justiça e Negócios } \\
\text { Interiores, de } 21 \text { de } \\
\text { setembro de } 1922\end{array}$ & $\begin{array}{l}\text { Atualiza e manda observar as instruções } \\
\text { para a execução do Decreto n. } 1.825 / 1907 \text {. }\end{array}$ \\
\hline 1930 & $\begin{array}{l}\text { Instruções, de } 19 \text { de } \\
\text { dezembro de } 1930\end{array}$ & $\begin{array}{l}\text { Atualiza e manda observar as instruções } \\
\text { para a execução do Decreto n. } 1.825 / 1907 \text {. }\end{array}$ \\
\hline 1966 & $\begin{array}{l}\text { Projeto de Lei n. } 3.746 \text {, } \\
\text { de } 24 \text { de junho de } 1966\end{array}$ & $\begin{array}{l}\text { Dispõe sobre a remessa de documentos } \\
\text { gráficos e audiovisuais à Biblioteca Nacional } \\
\text { e à Biblioteca da Câmara dos Deputados (o } \\
\text { projeto foi arquivado em 1979). }\end{array}$ \\
\hline 1969 & $\begin{array}{l}\text { Decreto-lei n. 824, de } 05 \\
\text { de setembro de } 1969\end{array}$ & $\begin{array}{l}\text { Concede o depósito legal ao Instituto } \\
\text { Nacional do Livro. }\end{array}$ \\
\hline 1985 & $\begin{array}{l}\text { Projeto de Lei n. } 5.528, \\
\text { de } 22 \text { de maio de } 1985\end{array}$ & $\begin{array}{l}\text { Determina a obrigatoriedade do depósito } \\
\text { legal para os softwares produzidos no país } \\
\text { (o projeto foi arquivado em 1987). }\end{array}$ \\
\hline 1985 & $\begin{array}{l}\text { Projeto de Lei n. } 5.529, \\
\text { de } 27 \text { de maio de } 1985\end{array}$ & $\begin{array}{l}\text { Propõe uma atualização do Decreto } \\
1.825 / 1907 \text { (o projeto foi arquivado em } \\
1989 \text { ). }\end{array}$ \\
\hline 1989 & $\begin{array}{c}\text { Projeto de Lei n. } \\
\text { de } 05 \text { de outubr } \\
1989\end{array}$ & $\begin{array}{l}\text { Propõe uma revisão e ampliação do Decreto } \\
1.825 / 1907 \text { (deu origem à Lei n. } \\
10.994 / 2004 \text { ). }\end{array}$ \\
\hline 1995 & $\begin{array}{l}\text { Projeto de Lei n. 1.128, } \\
\text { de } 109 \text { de outubro de } \\
1995\end{array}$ & $\begin{array}{l}\text { Propõe uma atualização do Decreto } \\
1.825 / 1907 \text { (o projeto foi arquivado em } \\
2000 \text { ). }\end{array}$ \\
\hline 2004 & $\begin{array}{l}\text { Projeto de lei n. 3.997, } \\
\text { de } 11 \text { de agosto de } \\
2004\end{array}$ & $\begin{array}{l}\text { Dispõe sobre a remessa, o depósito legal e } \\
\text { a guarda de obras culturais à Biblioteca } \\
\text { Nacional (o projeto foi arquivado em 2004). }\end{array}$ \\
\hline 2004 & $\begin{array}{l}\text { Lei n. } 10.994 \text {, de } 14 \text { de } \\
\text { dezembro de } 2004\end{array}$ & Revoga o Decreto n. $1.825 / 1907$ \\
\hline 2006 & $\begin{array}{l}\text { Projeto de Lei n. } 7.026 \\
\text { de } 15 \text { e maio de } 2006\end{array}$ & $\begin{array}{l}\text { Altera a Lei n. 10.994/2004, determinando o } \\
\text { repasse à Biblioteca Nacional de Brasilia de } \\
\text { um exemplar de cada publicação depositada } \\
\text { na Biblioteca Nacional do Rio de Janeiro (o } \\
\text { projeto foi arquivado em 2008). }\end{array}$ \\
\hline 2012 & $\begin{array}{l}\text { Projeto de Lei n. 3085, } \\
\text { de } 02 \text { de janeiro de } \\
\qquad 2012\end{array}$ & $\begin{array}{l}\text { Altera a Lei n. 10.994/2004, conferindo à } \\
\text { Biblioteca Nacional de Brasilia e às } \\
\text { bibliotecas públicas estaduais e do Distrito } \\
\text { Federal a condição de depositárias legais de } \\
\text { publicações (o projeto foi arquivado em } \\
\text { 2013). }\end{array}$ \\
\hline
\end{tabular}

FIGURA 1 - Cronologia do depósito legal no Brasil

Conforme já foi mencionado, no Brasil, a Biblioteca Nacional assume as principais funções da agência bibliográfica nacional, porém não de maneira exclusiva. Colaboram, neste sentido, mais três instituições nacionais: o Instituto Brasileiro de Informação em 
Ciência e Tecnologia (IBICT), que responde pelo Catálogo Coletivo Nacional de Publicações Seriadas (CCN) e pelo controle do número padrão para publicações seriadas, o International Standard Serial Number (ISSN); e a Câmara Brasileira do Livro (CBL), que, em parceria com o Sindicato Nacional de Editores de Livros (SNEL), controla o programa de catalogação na fonte brasileiro. (CAMPELLO, 2006).

\section{ANÁLISE DA LEI DE DEPÓSITO LEGAL BRASILEIRA}

A partir da revisão de literatura sobre o sistema de depósito legal de publicações e tendo como elemento norteador a obra de Larivière - Guidelines for legal deposit legislation, publicada em 2000, elaborou-se treze questões chave, as quais foram estabelecidas visando à análise da lei que regula o depósito legal no Brasil. As perguntas e respostas encontram-se dispostas sequencialmente no texto.

\section{1) Sobre a norma que regula o depósito legal no Brasil, trata- se de lei específica sobre o tema ou esta se encontra incluída em outra lei?}

A lei brasileira é específica sobre depósito legal.

Sobre esta questão, observa-se a opinião de Larivière (2000, p. 9, trad. nossa):

É preferível que os sistemas de depósito legal sejam baseados en uma lei específica, promulgada pelo legislador em cada país. Assim, se evitará que possam se introduzir mudanças im portantes no sistema por simples decisão administrativa e sem o debate público que normalmente exigiria a emenda de uma lei.

O Brasil, como se pode observar através da cronologia do depósito legal apresentada na seção anterior, sempre teve a regulamentação do sistema de depósito legal nacional orientada por normas independentes, isto é, sem vínculo, dependência ou ligação a nenhuma outra norma específica, como, por exemplo, a que regula os direitos de propriedade intelectual. 


\section{2) Qual a entidade responsável pelo tratamento do material oriundo de depósito legal?}

As obras deverão ser entregues à Biblioteca Nacional, que tratará do material depositado ou repassará a outra entidade 1 dos exemplares recolhidos.

Em relação à entidade responsável pelo tratamento do material oriundo do depósito legal, percebe-se, através da literatura, que, frequentemente, esta é uma atribuição da biblioteca nacional, até mesmo porque é, em geral a agência bibliográfica nacional, tal como ocorre no Brasil.

\section{3) Quem são os responsáveis pelo envio dos exemplares destinados ao depósito legal?}

Os impressores e/ou os editores.

A lei brasileira apresenta uma definição do que vem a ser "Editor" e "Impressor", o que contribui para esclarecer quem são os responsáveis pelo envio do material para depósito. A este respeito, Uribe e Steenkist (2005) atentam para o fato de que o surgimento de novos meios de comunicação afeta diretamente os envolvidos no processo de produção das novas mídias, e salientam que alguns países já incorporaram outras funções como as de produtor, fabricante e distribuidor no rol dos responsáveis pelo depósito legal de publicações. Larivière $(2000$, p. 17 , trad. nossa) acrescenta, ainda, que

Para conseguir que se deposite todo o material publicado, é importante que a definição de "editor" seja o mais exaustiva possível, de modo que inclua os editores comerciais e privados, bem como os oficiais, sempre que viável do ponto de vista legal. É, também, essencial que a definição englobe os produtores de to do tipo de material não impresso, incluindo publicações eletrônicas materiais e imateriais.

\section{4) O envio é obrigatório ou opcional?}

O envio é obrigatório.

Sobre a obrigatoriedade do depósito legal de publicações, Larivière (2000) observa que suas finalidades, em geral, são suficientes para justificar tal determinação, "[...] embora haja quem argumente que 0 depósito legal sem compensação para 0 
depositante seja uma forma discriminatória de imposto ou confisco de bens privados." (LARIVIĖRE, 2000, p. 8, trad. nossa). Daí a importância de especificar, na legislação, os objetivos do depósito legal, tendo em conta, obviamente, as especificidades do sistema jurídico vigente.

\section{5) Qual a definição de depósito legal segundo a lei específica?}

No Brasil, é dada a seguinte definição de depósito legal:

[...] exigência estabelecida em lei para depositar, em instituições específicas, um ou mais exemplares, de todas as publicações produzidas por qualquer meio ou processo, para distribuição gratuita ou venda. (BRASIL, 2004, Art. 2)

Importante haver uma definição de depósito legal, via legislação, para que se evite confusão entre os objetivos e finalidades do depósito com os direitos autorais, por exemplo. Larivière (2000), em suas recomendações, sugere que, ao elaborar uma lei, deve-se buscar sempre fazê-lo de forma que seu texto seja - mais simples e claro possível, de fácil leitura, conciso, bem estruturado e preciso, e indica como regra geral que se evitem a ambiguidade e a imprecisão.

\section{6) Que tipo de material (suporte físico) é passível de depósito legal?}

Todas as publicações, produzidas por qualquer meio ou processo, são passíveis de depósito legal. A norma utiliza, ainda, o critério de territorialidade para determinar o depósito legal de publicações, ou seja, deverão ser depositadas todas as publicações produzidas no país ou no estrangeiro produzidas por editores residentes no país.

Em relação à tipologia documental a que a lei se aplica, Larivière (2000) aponta a importância de a possibilidade de flexibilização estar prevista na norma, uma vez que novos suportes de registro da informação surgem de maneira cada vez mais frequente e rápida. Assim, evita-se a necessidade de atualizações da lei a cada novo tipo de obra que surge, o que, em geral, é um processo bastante demorado. Igualmente, evita-se a perda dos primeiros materiais que tenham surgido até que a lei tenha passado pela atualização e os incorporado ao texto. 
O autor acrescenta, ainda, que

[...] qualquer tipo de material bibliográfico de biblioteca denominado assim para diferenciá-lo do material de arquivo deverá ser objeto de depósito legal na medida em que é distribuído ao público em geral e produzido em várias cópias. O depósito legal se aplica a todos os tipos de material impresso (livros, fas cículos, folhetos, mapas, etc.), à maior parte dos materiais audiovisuais (discos, películas, fitas de vídeo, multimídia, etc.), ao material de radiodifusão e às publicações eletrônicas (disquetes, CD-ROM, material on-line, etc.). (LARIVIĖRE, 2000, p. 21, trad. nossa)

Sobre o tipo de material bibliográfico passível de depósito, mesmo especificada a sua tipologia, poderão, ainda, surgir dúvidas sobre novas edições, traduções, formato físico, etc. Neste caso, a legislação brasileira deixa evidente uma lacuna, uma vez que não trata da questão.

Ainda sobre o tipo de material passível de depósito no Brasil, no sítio da Biblioteca Nacional (https://www.bn.br/sobrebn/deposito-legal) encontra-se a seguinte informação: "O que deve ser enviado para o Depósito Legal: Livros, Periódicos, Partituras, Fonogramas, Videogramas." (BIBLIOTECA NACIONAL, 2016). A informação disponibilizada diz respeito às duas leis que regulam o depósito legal no Brasil, no entanto diverge daquela dada pela lei de materiais bibliográficos, uma vez que esta é bem clara ao definir que todo tipo de publicação, produzido em qualquer meio ou suporte, deverá ser depositado, e não somente livros e periódicos.

\section{7) Qual o número de exemplares a ser enviado?}

A lei brasileira exige 1 ou mais exemplares.

Sobre o número de exemplares exigidos para fins de depósito, observa-se que, em geral, é determinado em função da quantidade de exemplares necessários para cumprir a finalidade da coleção, ou seja, preservar o material e torná-lo acessível ao público. A legislação brasileira, neste caso, deixa a desejar, uma vez que não esclarece a quantidade de exemplares, deixando a cargo do depositante doar 1 ou quantos preferir. Seria interessante especificar a quantidade desejada e, preferencialmente, exigir mais de 1 exemplar, até mesmo porque a legislação brasileira sobre direitos autorais não permite a reprodução de obras, a não ser mediante expressa autorização do autor, o que impede a Biblioteca Nacional de confeccionar, por exemplo, uma cópia da obra depositada, caso o seu exemplar se perca/danifique. 


\section{8) Os objetivos do depósito legal estão claramente explicitados?}

Sim. O Art. $1^{\circ}$ explica seus objetivos de maneira clara: "[...] assegurar o registro e a guarda da produção intelectual nacional, além de possibilitar o controle, a elaboração e a divulgação da bibliografia nacional.".

\section{9) A norma expõe de forma clara quem é o proprietário da coleção de depósito legal?}

Subentende-se, através da norma, que a proprietária da coleção seja a Biblioteca Nacional, podendo esta repassar a outras entidades 1 dos exemplares recolhidos. Não está dito, porém, de maneira clara na lei a quem pertence a coleção, formada através de depósito legal. Larivière $(2000$, p. 12 , trad. nossa) ressalta a importância desta informação:

Deve estar claramente determinado na lei que a coleção é parte integrante do patrimônio cultural do país e que a única proprietária é a instituição nacional encarregada de sua manutenção e preservação.

\subsection{0) Estão previstas sanções para o caso de ocorrência do não cumprimento da norma? De que tipo?}

Sim: multa correspondente a cem vezes o valor da obra no mercado e apreensão de exemplares.

Sobre a aplicação de sanções no caso de descumprimento da lei, Larivière (2000) chama a atenção para sua relevância, uma vez que se torna complicado fazer com que se respeite uma norma que conta unicamente com a boa vontade do depositante. Ao mesmo tempo, salienta que a sua aplicação deve ser feita somente quando não há outra alternativa, uma vez que o objetivo da lei de depósito legal não é a aplicação de multas e penalidades.

\subsection{1) Existe alguma cláusula específica na norma que oriente sobre a preservação do material depositado?}

Sim, a BN reserva-se o direito de determinar a substituição de todo e qualquer exemplar que apresente falha de integridade física. 
A Biblioteca Nacional brasileira observa, somente, a necessidade de integridade do material na ocasião do depósito. Não apresenta, porém, cláusula específica que trate da preservação dos exemplares pós-depósito legal. Esta é uma questão a ser pensada, pois a preservação do material, em algumas situações, tem implicações sobre os direitos de propriedade intelectual - quando é necessário, por exemplo, reproduzir (criar uma cópia) de um material impresso que está se danificando pelo uso; ou realizar a conversão de uma mídia para outra mais moderna, como é o caso dos disquetes ou fitas VHS. Seria importante que as bibliotecas nacionais previssem estas questões via legislação, tendo autonomia e respaldo legal para fazer uso das medidas tecnológicas de preservação sempre que necessário.

\subsection{2) Existe alguma cláusula específica na norma que oriente sobre o acesso ao material depositado?}

Não há especificação sobre a forma de acesso ao material depositado através da lei brasileira de depósito legal. Sobre esta questão, Larivière (2000) recomenda que a legislação preveja o acesso à coleção nacional, tanto aos pesquisadores locais quanto estrangeiros, evitando possíveis situações constrangedoras futuras, como por meio da concessão de privilégios a um determinado grupo em detrimento de outro. Para o autor,

[...] uma legislação eficaz sobre depósito legal garante aos cidadãos e pesquisadores do país e do estrangeiro o acesso às coleções de investigação do material publicado no país. O controle bibliográfico e a possibilidade de acesso à coleção nacional são também dois objetivos internacionais da IFLA e da UNESCO, a saber, os programas de Controle Bibliográfico Universal (CBU) e Disponibilidade Universal de Publicações (UAP), aos quais todos os países são convidados a aderir. (LARIVIĖRE, 2000, p. 4, trad. nossa)

\subsection{3) Qual o prazo para a realização do depósito?}

Até 30 dias após a publicação da obra.

Sobre o prazo para realização do depósito legal, Larivière (2000), ao analisar diferentes leis nacionais, observaram que não há um padrão, variando muito de país para país. Sua orientação para determinação do prazo se baseia somente no bom senso, lembrando que, quanto antes for feito o depósito de uma obra, mais 
rápido se atenderá às necessidades dos usuários que buscam por publicações novas e mais rapidamente estas serão incorporadas à bibliografia nacional.

\section{CONSIDERAÇÕES FINAIS}

Mudanças de paradigma vem moldando, ao longo da história, as finalidades do depósito legal. O paradigma atual faz com que o objetivo principal do depósito legal convirja para a preservação do patrimônio cultural e a construção de uma memória documental nacional.

O Brasil apresenta uma lei específica sobre o depósito legal de publicações. Os materiais depositados são gerenciados pela agência bibliográfica nacional que, neste caso, é a Biblioteca Nacional. Até aqui, tudo de acordo com as recomendações da UNESCO e da IFLA para a consolidação do CBU. Alguns problemas surgem, no entanto, ao analisar mais a fundo a prática do depósito na BN. O que se percebe, em primeiro lugar, é que a instituição exige o depósito, atualmente, de apenas dois tipos de materiais bibliográficos: os livros e os periódicos. Todos os demais materiais citados na Lei 10.994/2004, simplesmente, não precisam ser depositados. A Declaração da IFLA sobre o depósito legal (2011) é bastante clara a este respeito:

Ao garantir que cópias de todas as publicações nacionais em todos os tipos de mídia sejam fornecidas aos depositários de confiança, o depósito legal permite e assegura a coleção completa do patrimônio documental de uma nação. [...] O depósito legal apoia a preservação, contribuindo para a sobrevivência a longo prazo do patrimônio documental de uma nação. Em última análise, o depósito legal é fundam ental para a liberdade de informação e para a perpetuação de uma cidadania informada. (FEDERAÇÃO INTERNACIONAL DAS ASSOCIAÇÕES DE BIBLIOTECÁRIOS E BIBLIOTECAS, 2011, p. 1, trad. nossa)

Uma lei de depósito legal não substitui políticas governamentais. Através da análise da lei brasileira n. 10.994/2004, observa-se que esta, em grande parte, segue as recomendações da UNESCO/IFLA: apresenta texto claro, preciso, desprovido de trechos ambíguos, informa os objetivos do depósito legal, esclarece qual instituição é responsável pela coleção, prevê sanções no caso do seu descumprimento, apresenta um prazo razoável para que o depósito seja realizado, explica quem são os depositários do 
material bibliográfico. Algumas questões poderiam ter sido tratadas, na própria lei, como, por exemplo: a definição exata da quantidade de exemplares a serem enviados para depósito (preferencialmente, mais de 1 exemplar); a forma de acesso ao material depositado; a entidade proprietária da coleção formada via depósito legal. Outra questão importante que a lei brasileira não aborda é a da preservação do material depositado. A esse respeito, seria interessante incorporar, na lei, a previsão da possibilidade da realização de cópias e a conversão de mídias pela BN para fins de preservação.

Enfim, a existência de uma lei nacional que regulamenta o sistema de depósito legal de um país sugere a relevância dispensada por este mesmo país ao seu patrimônio bibliográfico. Da mesma forma, o tratamento dado a este material, pós depósito, demonstra, também, o reconhecimento de sua importância para a cultura da nação. O Brasil, nesse quesito, demonstra o reconhecimento ao seu patrimônio, buscando proporcionar condições aos cidadãos de ter acesso a essas fontes de informação, contribuindo para a formação de sua consciência histórica e reconhecimento identitário. Convém apenas rever as práticas estabelecidas, coadunando os objetivos do depósito legal, explicitados na lei, com a realidade da instituição depositária, a qual vem buscando, desde o princípio, atender às demandas impostas, muitas vezes carecendo de recursos (financeiros, humanos, físicos) para cumprir tanto a missão de biblioteca da nação quanto às determinações de uma agência bibliográfica nacional.

\section{REFERÊNCIAS}

BRASIL. Decreto n.- 1.825, de 20 de dezembro de 1907. Dispõe sobre a remessa de obras impressas à Bibliotheca Nacional. Rio de Janeiro, 20 de dezembro de 1907. Disponível em: <https://goo.gl/O4G4dY >. Acesso em: 11 ago. 2016.

. Lei n.- 10.994, de 14 de dezembro de 2004. Dispõe sobre o depósito legal de publicações, na Biblioteca Nacional, e dá outras providências. Brasília, 14 de dezembro de 2004. Disponível em: <https://goo.gl/m2VIVy>. Acesso em:11 ago. 2016.

. Lei n.- 12.192, de 14 de janeiro de 2010. Dispõe sobre o depósito legal de obras musicais na Biblioteca Nacional. Bras ília, 14 de janneiro de 2010. Disponível em: <https://goo.gl/mULFlb>. Acesso em:12 ago. 2016.

BIBLIOTECA NACIONAL (Brasil). Depósito legal. Rio de Janeiro, [2016]. 
Disponível em:<https://goo.gl/AM5jwA>. Acesso em:12 set. 2016.

CAMPELLO, Bernadete. Introdução ao controle bibliográfico. 2. ed. Brasília:Briquet de Lemos Livros, 2006.

DOUGNAC, Marie-Thérèse; GUILBAUD, M. Le dépôt légal: son sens et son évolution. Bulletin des Bibliothèques de France, Paris, n. 8, Août 1960. Disponível em: <http://goo.gl/nQogl9>. Acesso em:28 jun. 2016.

FEDERAÇÃO INTERNACIONAL DAS ASSOCIAÇÕES DE BIBLIOTECÁRIOS E BIBLIOTECAS. IFLA Statement on Legal Deposit. Den Haag, 2011. Disponível em: <https://goo.gl/QJMXpR>. Acesso em: 12 set. 2016.

LARIVIÈRE, Jules. Legislación sobre depósito legal: directrices. Paris: UNESCO, 2000. Edição revisada, aumentada e atualizada da publicação de 1981 de Jean Lunn. Disponível em: <http://goo.gl/cAcsRd>. Acesso em: 28 jun. 2016.

LUNN, Jean. Guidelines for legal deposit legislation. Paris: UNESCO, 1981. Disponível em:<https://goo.gl/QBbPLi>. Acesso em:05 jul. 2016.

ORGANIZAÇÃO MUNDIAL DA PROPRIEDADE INTELECTUAL. Reseña del Convenio de Berna para la Protección de las Obras Literarias y Artísticas, (1886). Genéve, [2015]. Disponível em: <http://goo.gl/krx×2r>. Acesso em:28 jul. 2016.

PABÓN CADAVID, Jhonny Antonio. Introducción al depósito legal como herramienta para el patrimonio documental. La propiedad inmaterial, Bogotá, n. 17, p. 113-144, nov. 2013. Disponível em: <https://goo.gl/oceSIn>. Acesso em:26 set. 2016.

PINHEIRO, Ana Virgínia. Glossário de codicologia e documentação. Anais da Biblioteca Nacional, Rio de Janeiro, v. 115, p. 123-213, 1995. Disponível em: <https://goo.gl/mxEOkd>. Acesso em:12 abr. 2016.

PINTO, Mônica Rizzo Soares. Preservação de publicações eletrônicas: a questão do depósito legal. Rio de Janeiro, 2011. Dissertação (Mes trado) Programa de Pós-Graduação em Memória Social, Universidade Federal do Estado do Rio de Janeiro, 2011. Disponível em: <http://goo.gl/CCc4Az>. Acesso em: 14 abr. 2016.

URIBE, Richard; STEENKIST, Robert Max. El depósito legal en los países de Latinoamérica en 2005: su vigencia y normatividad, estadísticas comparativas. Bogotá: Cerlalc, 2005. Disponível em:<http://goo.gl/UNFJi5>. Acesso em:28 jul. 2016. 
